\title{
6. DESMONTE E FINANCEIRIZAÇÃO DA SEGURIDADE SOCIAL EM TEMPOS DE PANDEMIA*
}

Daniele Batista Brandt Juliana Fiuza Cislaghi

\section{Introdução}

Em 11 de março a Organização Mundial de Saúde (OMS) decretou que a epidemia de Sars-Covid-19 iniciada na China, tinha se transformado em pandemia, isto é, que os casos se multiplicaram em diversos países e se generalizaram pelo mundo. O Brasil começou a debater a epidemia ainda em fevereiro, quando no dia 06 Bolsonaro sancionou a primeira lei sobre as normas de quarentena e combate ao coronavírus e no dia 09 chegaram ao país 34 brasileiros que viviam em Wuhan, primeiro foco conhecido da pandemia. 0 primeiro caso no Brasil, primeiro também na América Latina, foi registrado em 26 de fevereiro em São Paulo: um homem de 61 anos, assintomático, que voltava da Itália, país que então tinha o maior número de mortos, no total de 15,8 mil. Em 11 de março, dia do decreto da pandemia pela OMS, o Distrito Federal foi a primeira unidade da federação a suspender as aulas na rede pública e privada e, alguns dias depois, atividades comerciais e de serviços ${ }^{1}$.

As medidas de quarentena e distanciamento social, a partir daí, tornaram-se objeto de disputa política entre governadores e o governo federal, entre a base de sustentação do governo e sua oposição e em meio à negação dos dados científicos e a defesa "da vida continuar" feita pelo presidente os trabalhadores se viram expostos à doença e sem garantia de renda para sua sobrevivência.

São muitas as análises necessárias sobre essa conjuntura mais recente, que segue seu curso. Em meados de setembro, quando es-

\footnotetext{
*DOI- 10.29388/978-65-86678-47-5-f.159-180

1 Disponível em: <https://g1.globo.com/bemestar/coronavirus/noticia/2020/04/06/coronavirus-veja-a-cronologia-da-doenca-no-brasil.ghtml>. Acesso em: 19 set. 2020.
} 
crevemos essas linhas, ainda que a pandemia desse sinais de redução ${ }^{2}$, o Brasil seguia em abertura total das atividades econômicas após acumular mais de 134 mil mortes, 4,4 milhões de casos notificados e sob uma alarmante média móvel de 789 mortes por Covid-19 por dia nos últimos 15 dias $^{3}$.

Nesse capítulo analisaremos a conjuntura brasileira em que chega ao país a pandemia e sua influência nas medidas tomadas para os trabalhadores sobreviverem a suas consequências econômicas e sociais. Centraremos no percurso recente da política de assistência social e, a praticamente única, proposta implementada: a transferência de renda por meio do auxílio emergencial. Além disso, levantaremos alguns elementos que podem apontar para os caminhos futuros do desmonte e financeirização em curso da Seguridade Social no Brasil, a partir das propostas e medidas recentes do governo.

\section{Crise do capital, ultraneoliberalismo e pandemia}

A História do capitalismo pode ser contada por uma sucessão de crises inerentes a esse modo de produção que, diferente de outros momentos da humanidade, não se constituem como crises de escassez, mas, como crises de superacumulação, quando os capitais existem em excesso e não conseguem, assim, realizar suas expectativas de lucro (Fontes, 2020).

Meszáros (2011) caracteriza a crise que ascende em fins da década de 1960 como uma crise estrutural porque tem a particularidade de se constituir em um momento em que os recursos naturais que alimentam o crescimento exponencial do capital encontram-se no limite da sua saturação colocando em xeque a sobrevivência do planeta. De lá para cá, o capitalismo teve alguns episódios de curta recuperação, mas, em meio a crises agudas cada vez mais profundas e frequentes, com respostas políticas da classe dominante que impu-

\footnotetext{
2 Disponível em: <https://agencia.fapesp.br/quarta-fase-da-epicovid-indica-desaceleracaoda-epidemia-na-maior-parte-do-pais/34162/>. Acesso em: 19 set. 2020.

${ }^{3}$ Disponível em:

<https://www.em.com.br/app/noticia/nacional/2020/09/16/interna nacional,1186144/ brasil-registra-media-movel-diaria-de-789-mortes-por-covid-19.shtml>. Acesso em: 19 set. 2020.
} 
seram retrocessos econômicos e sociais para a absoluta maioria da população mundial.

A resposta da classe dominante à crise estrutural foi o que se convencionou chamar de neoliberalismo, que no decorrer das décadas de 1970, 1980 e 1990 tornou-se o modelo hegemônico mundial, sobretudo depois da derrota do socialismo real na URSS e nos países do leste da Europa. O neoliberalismo, então, desde as últimas décadas do século XX, passa a se apresentar como "nova razão do mundo" (DARDOT e LAVAL, 2016), responsável pela expropriação de bens naturais comuns e privatização de sistemas sociais geridos e financiados pelos Estados por meio dos fundos públicos.

Na primeira década dos anos 2000, as lutas sociais dos trabaIhadores contra esses ataques permanentes às suas condições de vida e aos parcos direitos conquistados no período pós-guerra, ou mesmo a perspectiva desses direitos na periferia do capital, pareceram melhorar a correlação de forças com a eleição de governos compostos por líderes, partidos e movimentos sociais oriundos da classe trabalhadora, forjados nas resistências construídas no período anterior. Sobretudo na América Latina, venceram as eleições governos do campo dito progressista como Lula, Morales, Corrêa e Lugo (SANTOS, 2018).

O balanço desses governos, no entanto, demonstra que seus efeitos reais ficaram muito aquém das expectativas de suas bases sociais. Ao contrário, a manutenção das políticas econômicas de sustentação do neoliberalismo só garantiu pequenos avanços sociais devido, em grande parte, a riqueza gerada pelo agronegócio e pelo neoextrativismo que aprofundaram mecanismos de expropriação que se enfrentavam diretamente com a reivindicação dos movimentos indígena e Sem Terra (SVAMPA, 2019).

A financeirização, traço característico do período neoliberal, seguiu garantindo a hegemonia dessa fração do capital na economia mundial e foi o mercado financeiro o detonador da aguda crise de 2008, que se iniciou nos EUA alcançando, em tempos distintos, todos os países. Muitos autores partem da hipótese de que a crise de 2008 é um marco determinante para a aceleração dos processos de expropriação, privatização e exploração cada vez mais brutal dos trabalha- 
dores para que os lucros se mantivessem em seus patamares anteriores. Isso justificaria a utilização do termo ultraneoliberalismo para caracterizar a conjuntura mundial a partir de então, em um sentido adjetivo de aceleração e aprofundamento do que já era característica histórica do neoliberalismo (ANTUNES, 2018).

Para sustentar esse novo cenário a burguesia passou a investir em rupturas institucionais que vêm tornando a democracia burguesa formal ainda mais blindada a qualquer reivindicação organizada dos trabalhadores que interrompa ou altere o curso desse processo. Os governos anteriores do ciclo progressista, representantes do projeto neoliberal progressista nos termos de Fraser (2020), são então substituídos por toscos representantes do neofascismo. Esses governos são apoiados pela grande burguesia e por segmentos médios, e mesmo pelos mais precarizados trabalhadores ganhos pela ideologia do conservadorismo evangélico, ressentidos pelos efeitos causados pelo próprio neoliberalismo, mas que atribuem aos anteriores representantes da esquerda o retrocesso nas suas condições de vida. Retomase fortemente o machismo, o racismo, a xenofobia, a lgbti+fobia em oposição a todos os avanços civilizatórios conquistados ou reivindicações que alcançaram maior visibilidade no último período.

No Brasil, as manifestações de 2013 foram o primeiro sinal do esgotamento do ciclo petista como experiência nacional do neoliberalismo progressista e seus mecanismos de cooptação (CISLAGHI, 2020). Os efeitos da crise de 2008 começaram a ser sentidas em 2014 e a reeleição de Roussef, com pequena margem de diferença na votação, se encerrou no golpe parlamentar, jurídico e midiático articulado por representantes da burguesia antigos aliados, inclusive Temer, seu vice-presidente, que assumiu o governo e se manteve até as eleições de 2018, apesar dos recordes de impopularidade.

O governo golpista de Temer já reposicionou o Brasil nos marcos do ultraneoliberalismo. Apesar de não ter conseguido aprovar sua proposta de contrarreforma da Previdência a aprovação da PEC de teto dos gastos, que congelou em 20 anos qualquer aumento real de recursos para políticas públicas no orçamento da União, foi um avanço qualitativo no ajuste fiscal permanente que marcou o modelo econômico neoliberal no Brasil desde o fim da ditadura (BEHRING, 
2019). A transferência de fundo público para o capital financeiro por meio, principalmente, dos juros e amortizações da dívida pública ganha um instrumento constitucional como garantia acima dos processos políticos e eleitorais.

Nas eleições de 2018, a descrença na chamada "política tradicional" bloqueou as possibilidades eleitorais dos representantes legítimos dos partidos burgueses que desembarcaram, sem escrúpulos, na candidatura do neofascista Jair Bolsonaro. Seu primeiro ano de governo garantiu a aprovação de nova contrarreforma da Previdência que avançou no desmonte dos direitos de aposentadorias e pensões, aumentando prazos e percentuais de contribuição e reduzindo benefícios. Sob o comando de Paulo Guedes como Ministro da Economia, representante direto dos interesses do mercado financeiro e formado pela escola econômica que geriu a ditadura de Pinochet no Chile, a ortodoxia ultraneoliberal se associou a um discurso ultraconservador de responsabilização individual, dessolidarização, desamparo e desproteção aos segmentos mais pauperizados.

Foi nesse cenário de avanço na barbárie social que a pandemia chegou ao país. No mundo inteiro os graves efeitos sanitários vêm sendo detonadores de uma nova agudização da crise do capital, de contornos inéditos. Somam-se ao vírus condições precárias de abastecimento de água e esgoto, condições de moradia, precarização de vínculos e condições de trabalho e ampliação do desemprego, aumento do preço dos alimentos, ampliação das desigualdades educacionais - que tendem a se aprofundar por anos e uma crise de representatividade política, que ameaça permanentemente a democracia, mesmo em seus mecanismos formais (FONTES, 2020).

Nada disso impediu que os representantes do grande capital seguissem ampliando seus lucros mesmo no auge da pandemia e mesmo com o decrescimento do Produto Interno Bruto (PIB) na maioria dos países. Segundo dados da Oxfam (2020) a pandemia significou ampliação das desigualdades entre classes sociais e profunda concentração e centralização do capital, em detrimento de pequenos negócios.

No mundo inteiro, estima-se a perda de 400 milhões de empregos ao mesmo tempo em que as 32 empresas mais lucrativas do 
mundo devem faturar 577 bilhões de dólares a mais em 2020. Sob a égide do ultraneoliberalismo, os lucros das 500 maiores empresas do mundo cresceram 156\% entre 2009 e 2019, recursos que foram em $90 \%$ repassados a seus principais acionistas. Ainda assim, em 2020, 32 maiores empresas já distribuíram $94 \%$ dos seus lucros estimados entre janeiro e setembro para os acionistas. Entre março e o fim de maio, as 25 pessoas mais ricas do mundo cresceram suas fortunas em 255 bilhões de dólares. No Brasil, 33 pessoas tornarem-se novos bilionários durante a pandemia. As anunciadas doações empresariais filantrópicas, que tanto serviram como marketing empresarial no período, só alcançaram, porém, 0,5\% do lucro operacional das 32 mais lucrativas empresas do mundo em 2019 (OXFAM, 2020).

Enquanto isso, estima-se que meio bilhão de seres humanos passarão à condição de pobreza e, até o fim de 2020, mais gente morrerá de fome do que das consequências imediatas da contaminação por Covid. No Brasil, a pesquisa Epicovid ${ }^{4}$ indicou que os $20 \%$ mais pobres dentre a população têm uma prevalência de contágio por Covid duas vezes superior aos $20 \%$ mais ricos e são predominantemente pretos e pardos. A doença também é mais letal entre pretos e pardos que, quando foram internados, tiveram $55 \%$ de mortes enquanto os brancos tiveram $38 \%$, em dados de maio ${ }^{5}$.

Assim, as pesquisas demonstram que a pandemia não atinge a todos da mesma forma, ao contrário, a pandemia apresenta-se ao grande capital como oportunidade para os negócios. Apesar disso, renova-se a "pedagogia da cultura da crise" como forma de sustentação da hegemonia do capital

[...] através dos quais a burguesia e seus associados tentam tornar universais os seus interesses específicos para obter o consentimento passivo e ativo das classes subalternas em torno de seu projeto societal (MOTA, 2019, p.136).

\footnotetext{
4 Disponível em: <https://agencia.fapesp.br/quarta-fase-da-epicovid-indica-desaceleracaoda-epidemia-na-maior-parte-do-pais/34162/>._. Acesso em: 24 set. 2020.

${ }^{5}$ Disponível em: <https://agencia.fapesp.br/quarta-fase-da-epicovid-indica-desaceleracaoda-epidemia-na-maior-parte-do-pais/34162/>. Acesso em: 24 set. 2020.
} 
Nas próximas seções analisaremos as medidas do governo Bolsonaro que, ao supostamente enfrentar a "crise nacional" aprofundada pela pandemia, aceleram o desmonte, a privatização e a financeirização da Seguridade Social no Brasil.

\section{Assistência Social pós-golpe e as limitadas respostas do governo aos efeitos sociais da pandemia}

Dentre as políticas que compõem o sistema de Seguridade Social brasileiro, a Assistência Social foi a que levou maior tempo para sua construção. Apesar do seu reconhecimento como direito social na Constituição Federal de 1988, foi a política que mais encontrou resistências à superação de um modelo assistencialista, caritativo e primeiro damista. Desde a citada Carta, foram necessários cinco anos até a sua regulamentação pela Lei Orgânica da Assistência Social (LOAS) de 1993, e mais doze anos para a conformação de um Sistema Único da Assistência Social (SUAS) em 2005. Entretanto, do golpe de 2016 até este segundo ano do governo Bolsonaro, foi um dos setores que mais expressou o ávido processo de desmonte e financeirização das políticas sociais no país.

Durante o Governo Temer, o Ministério do Desenvolvimento Social (MDS) foi conduzido por dois médicos que lhe prescreveram um amargo receituário: os ministros Osmar Terra e, em seguida, Alberto Beltrame chancelaram a retomada do primeiro damismo nos programas de assistência social através do Programa Criança Feliz de Marcela Temer, ao mesmo tempo em que promoveram a revisão de 472,3 mil benefícios previdenciários - Auxílio Doença e Aposentadoria por Invalidez - o que resultou no cancelamento de $78 \%(369,6$ mil) destes benefícios ${ }^{6}$.

Além disso, promoveram a revisão do benefício assistencial das pessoas idosas e com deficiência - o Benefício de Prestação Continuada (BPC) previsto na LOAS - e tornaram obrigatória a inscrição dos seus beneficiários no Cadastro Único do Governo (Cadúnico). Cabe destacar que a prioridade dada à revisão dos benefícios do Ins6 Disponível em: $\quad<$ https://www1.folha.uol.com.br/mercado/2019/01/pente-fino-do-inss-
corta-mais-beneficios-que-o-previsto.shtml>. Acesso em; 21 set. 2020. 
tituto Nacional do Seguro Social (INSS) resultou na morosidade no processo de concessão de novos benefícios assistenciais, cujo tempo médio de análise passou de dois meses para aproximadamente um ano. $E$, com relação aos benefícios assistenciais previstos no Programa Bolsa Família (PBF), muito embora tenham garantido um reajuste de aproximadamente $5 \%$, promoveram o desligamento de aproximadamente $3 \%$ das famílias beneficiárias ${ }^{7}$.

O Governo Bolsonaro seguiu no "tratamento" proposto pelo governo anterior, novamente sob o comando de Osmar Terra: o Programa Criança Feliz de Marcela Temer, foi assumido por Michelle Bolsonaro, passando a receber privilégio orçamentário, e foi mantida a mesma "conduta" para a concessão e a revisão dos benefícios. A novidade foi a perda de status da política de Assistência Social, reduzida a subsecretaria, após a unificação do MDS com o Ministério do Esporte no Ministério da Cidadania ( $\mathrm{MC}$ ), posteriormente assumido pelo médico veterinário e deputado federal da base do governo, Onyx Lorenzoni.

Além disso, a iniciativa de revisão de benefícios do INSS, foi alçada à condição de programa, através da criação de um Programa Especial para Análise de Benefícios com Indícios de Irregularidade (Programa Especial), inclusive com a institucionalização de um bônus de desempenho institucional aos trabalhadores do Instituto para análise e perícia destes benefícios, através da Lei № 13.846/2019. Ao mesmo tempo, o Governo passou a não disponibilizar os dados sobre as novas concessões de benefícios assistenciais do PBF, apesar de prevista na Lei de Acesso à Informação ${ }^{8}$, obscurecendo o tamanho da lista de espera para acesso ao Programa que, de acordo com o mesmo, foi (sub)estimada em 500 mil famílias no ano de 2019.

Cabe destacar que tais processos foram conduzidos já na vigência do "Novo Regime Fiscal" instituído pela lei do teto dos gastos. Ou seja, em meio a um claro processo de desmonte das políticas sociais e de suas instituições, inclusive pela ausência de reposição de servidores públicos, cuja admissão foi vedada pela referida legislação.

7 Disponível em: <https://nucleo.jor.br/governo/2020-03-03-bolsa-familia-dados-2019>. Acesso em: 21 set. 2020.

8 Lei 12.527 de 18 de novembro de 2011. Disponível em: <www.planalto.gov.br/ccivil 03/ Ato2011-2014/2011/Lei/L12527.htm>. Acesso em: 24 set. 2020. 
Paralelamente, o Governo Bolsonaro deu seguimento à agenda ultraneoliberal, com a aprovação da contrarreforma da Previdência, através da Emenda Constitucional № 103/2019. Mais uma vez, houve impactos diretos para a avaliação de benefícios previdenciários e assistenciais, em especial para aqueles solicitados após a reforma da previdência, haja vista a necessidade de adaptação do INSS e da DATAPREV, em um momento no qual seus quadros funcionais encontravam-se drasticamente reduzidos por aposentadorias, demissões e sem qualquer horizonte de novos concursos ou contratações. Logo antes à contrarreforma, o governo apresentou um plano de demissão voluntária aos trabalhadores do DATAPREV e incluiu a empresa no rol de aptas à privatização ${ }^{9}$.

Após a declaração da pandemia do novo coronavirus pela OMS, o Governo Bolsonaro se viu obrigado a anunciar um conjunto de medidas econômicas para enfrentamento da pandemia, dentre os quais a criação de um programa de transferência de renda, denominada por Auxílio Emergencial (AE). Inicialmente, o Governo apontou para a concessão de um benefício de $\mathrm{R} \$ 200,00$ aos trabalhadores informais durante um período de três meses. Contudo, a proposta provocou intenso debate e, sob pressão popular e articulação parlamentar, foi derrotada no Congresso Nacional, com a ampliação do benefício para $\mathrm{R} \$ 600,00$.

Nesse ínterim, um outro revés do governo no Congresso Nacional foi a aprovação da Lei № 13.981/2020, que modificou a LOAS e estabeleceu a ampliação do critério de concessão do BPC para pessoa idosa ou com deficiência integrante de família com renda mensal per capita de até um quarto do salário mínimo $(\mathrm{R} \$ 261,25)$ para até meio salário mínimo ( $R \$ 522,50)$. Contudo, uma semana depois foi publicada a Lei № 13.982/2020, que estabeleceu o adiamento da aplicação do novo critério até 31 de dezembro de 2020.

Esta mesma lei criou o Auxílio Emergencial (AE), benefício regulamentado pelo Decreto Presidencial № 10.316 e pela Portaria MC № 351, ambos de 7 de abril de 2020. Com o propósito de garantir

9 Disponível em: <https://www.assespropr.org.br/dataprev-cria-programa-de-demissaovoluntaria-e-aumenta-rumor-de-extincao-ouprivatizacao/\#: :text=\%20Dataprev\%20cria \%20programa\%20de\%20demiss\%C3\%A30\%20volunt\%C3\%A1ria\%20e,de\%20ades\%C3\%A3o. \%20De\%20acoredo\%20com\%20a...\%20More\%20>. Acesso em: 24 set. 2020. 
uma renda mínima aos brasileiros mais afetados durante a pandemia do novo coronavirus, o $A E$ foi direcionado aos trabalhadores informais maiores de 18 anos, contribuintes ou não ao INSS, que não recebessem nenhum outro benefício do Governo Federal (com exceção do PBF), integrantes de família com renda mensal per capita de até meio salário mínimo $(\mathrm{R} \$ 522,50)$ ou renda familiar mensal total de até três salários mínimos $(\mathrm{R} \$ 3.135,00)$ e isentos de declaração de Imposto de Renda em 2018. Contudo, cabe destacar, houve demora na regulamentação, na divulgação do calendário de pagamento e na efetiva liberação do recurso, em um contexto de profundas modificações nas condições de vida e trabalho da população brasileira.

De acordo com o Governo, o AE seria pago automaticamente aos trabalhadores que atendessem às regras e que estivessem cadastrados no Cadúnico e no PBF. Dados do MC do mês de agosto de $2020^{10}$ apontaram que 28,9 milhões de famílias, que correspondiam a pouco mais de 76,04 milhões de pessoas, estavam inscritas no $\mathrm{Ca}$ dúnico.

Desse universo do Cadúnico, 14,2milhões de famílias eram beneficiárias do PBF, das quais 661.012 famílias seguiram recebendo apenas os benefícios do Programa, cuja folha de pagamento totalizou um valor de quase $\mathrm{R} \$ 108,4$ milhões, com valor médio de benefício de $R \$ 164,13$ mensais por família. As demais 13,6 milhões de famílias beneficiárias do PBF passaram a receber em seu lugar o $A E$, cuja folha de pagamento totalizou um valor superior a $R \$ 15,1$ bilhões, com valor médio de benefício de $\mathrm{R} \$ 1.115,56$ por família.

Assim, observa-se que um número significativo de famílias beneficiárias do PBF não atendiam aos critérios de elegibilidade do $A E$, supostamente por possuírem vínculo formal de trabalho e/ou receberem benefícios assistenciais ou previdenciários, conforme cruzamentos de dados do governo federal, realizado pela DATAPREV. Ocorre que, no entanto, a maior parte dessas famílias beneficiárias do PBF ficaram impedidas de migrar para o AE por estarem aguardando a retomada da averiguação cadastral e cancelamento dos seus be-

\footnotetext{
${ }^{10}$ Disponível em:

<http://www.mds.gov.br/webarquivos/sala de imprensa/boletins/boletim bolsa familia/ 2020/setembro/boletim BFInforma730.html>. Acesso em: 21 set. 2020.
} 
nefícios, tendo em vista a suspensão dos processos operacionais e de gestão do PBF e do Cadúnico pela Portaria MC № 335/2020.

Muito embora o país conte há duas décadas com uma ferramenta para acesso aos programas sociais federais, o Cadúnico, o governo optou pela criação de mais um cadastro específico para o $\mathrm{AE}$, através de um site e de um aplicativo da Caixa. Foi o governo Cardoso que criou o formulário de Cadastramento Único para Programas Sociais do Governo Federal, através do Decreto № 3.877/2001. Efetivamente, o cadastro só passou a ser utilizado com a criação do PBF em 2003. Posteriormente, no governo Lula, o instrumento foi redimensionado, constituindo-se em uma base de dados para identificação e caracterização socioeconômica das famílias brasileiras de baixa renda e utilizado para seleção de beneficiários e integração de programas sociais do Governo Federal, e passou a ser chamado Cadúnico, através do Decreto № 6.135/2007.

Apesar da longevidade do Cadastro, impressiona a inexistência de ferramenta eletrônica online para o mesmo, muito embora a Portaria № 368/2020 e a Instrução Operacional № 4/2020, ambas publicadas no final do mês de abril, tenham autorizado e regulamentado a coleta dos dados para inclusão e atualização cadastral por telefone ou por meio eletrônico, enquanto durasse a situação de emergência ou o estado de calamidade pública gerado pela pandemia.

Apesar de toda a experiência do MDS e da existência de uma base de dados com mais de 76 milhões de cidadãos brasileiros cadastrados e potencialmente elegíveis ao auxílio, por que o governo não optou por um fluxo de concessão mediante o cadastro único eletrônico online que, além de já constituir uma demanda, está sob a responsabilidade de um conselho gestor interministerial? Por que optou por um fluxo de concessão baseado no cadastro do beneficiário mediante uma página e um aplicativo da instituição financeira operadora do benefício, a Caixa Econômica Federal (Caixa)?

Estamos diante de um gatilho à la Schrödinger: a lei de criação do AE não permitiu o acesso automático da população ao Cadúnico por meio digital mas estabeleceu que o mesmo será pago através de conta do tipo poupança digital, de forma automática. Segundo a exposição de motivos da Medida Provisória (MP) № 982/2020 a criação 
automática de conta tipo poupança digital para viabilizar o pagamento do auxílio emergencial mensal "promoveu a inclusão financeira de grande parte da população, que passa a ter acessos a serviços financeiros de forma eletrônica". Segundo o presidente do banco, a iniciativa possibilitou encontrar 36 milhões de "invisíveis" que não tinham conta bancária. A partir desta iniciativa, a Caixa se tornou o maior banco digital do mundo, com cerca de 120 milhões de clientes ${ }^{11}$. E, assim, a concessão de um benefício eventual revela-se mais um capítulo útil ao processo de financeirização das políticas sociais.

A Caixa é um banco nacional e público que historicamente atua como agente operador das políticas sociais implementadas pelo governo, tais como Fundo de Garantia por Tempo de Serviço (FGTS), Programa de Integração Social (PIS), Seguro Desemprego, Fundo de Financiamento ao Estudante do Ensino Superior (FIES), Sistema Financeiro de Habitação (SFH), Programa Minha Casa Minha Vida (PMCMV) e PBF.

Para operar o $A E$, foram firmados contratos entre o governo, por meio do MC, com a Caixa, a DATAPREV e os Correios ${ }^{12}$. No contrato com a Caixa, no valor de $\mathrm{R} \$ 414,32$ milhões coube à instituição desenvolver o aplicativo (APP) para solicitação do auxílio, desenvolver o APP de pagamento digital (Caixa Tem), abrir as agências aos sábados e em horário estendido e contratar serviço de armazenamento e de processamento. Com o DATAPREV, o contrato foi no valor de R\$ 19,08 milhões, para a qual coube analisar a elegibilidade, construir uma plataforma de informações ao cidadão e desenvolver um siste-

\footnotetext{
11 "A gente criou o maior banco digital do mundo. O maior até agora era um banco indiano, com 116 milhões de contas digitais. A gente vai superar, com 120 milhões de clientes reais. Não é aquele que você cria a conta e não tem utilização. Não estou nem juntando os clientes que a Caixa já tinha [93 milhões]. Esses acabam indo para o Internet banking, que é outro grupo. Estou falando dos 65 milhões do Auxílio [Programa de Auxílio Emergencial (PAE)], que devem virar 66 milhões, dos 5 milhões do Benefício Emergencial [BEm], aquele de manutenção de emprego, e dos 60 milhões do FGTS. Todos estão recebendo digitalmente. Como há alguma sobreposição, sobram 120 milhões", detalhou o Presidente da Caixa, Pedro Guimarães, em entrevista ao Valor em 23 de julho. Disponível em: $<$ https://www.frontliner.com.br/caixa-estuda-criar-o-maior-banco-digital-do-pais/>. Acesso em: 23 set. 2020.

${ }^{12}$ Disponível em:

$<$ https://www.gov.br/cidadania/pt-br/acoes-e-programas/covid-19/transparencia-egovernanca/auxilio-emergencial-1>. Acesso em: 23 set. 2020.
} 
ma para contestações e gerenciamento dos pagamentos judiciais. Aos Correios coube um contrato no valor de $\mathrm{R} \$ 58,6 \mathrm{mil}$, para realizar cadastramento assistido, o que, a nosso ver, deveria ter ocorrido, desde o início, por meio da política de Assistência Social e pelos dispositivos do SUAS.

Importa recuperar que o processo de desmonte que conduzia à privatização da Caixa foi interrompido durante os governos do PT, retomado com o golpe de 2016, e aprofundado desde a posse do governo Bolsonaro em 2019, sob a condução do ministro da Economia Paulo Guedes e do presidente da Caixa, Pedro Guimarães, dois economistas que se conheceram no banco BTG Pactual com vasta experiência no mercado financeiro e especialista em privatizações ${ }^{13}$.

Assim, não é mera coincidência que tramite no Congresso a MP № 995/2020, que permite o desmembramento e a privatização de subsidiárias da Caixa ${ }^{14}$. Segundo aponta a Federação Nacional das Associações do Pessoal da Caixa Econômica Federal (FENAE), essa proposta está voltada para as áreas mais rentáveis do banco, tais como seguridade, cartões, loterias e, obviamente, o banco digital. Conforme noticiado na imprensa ${ }^{15}$, em meio a uma crise econômica e sanitária sem precedentes, o presidente da Caixa se viu diante da "oportunidade" de viabilizar o "desinvestimento" de uma série de ativos e de abrir o capital de um recém-criado e gigantesco banco digital (ou quiçá privatizá-lo completamente).

As respostas aos pedidos de AE foram outro importante capítulo dessa história, marcado pela demora do processo de análise, na divulgação dos calendários, na liberação dos benefícios, além de miIhares de negativas que originaram recursos à tal decisão.

A grande maioria da população se viu impelida, em meio de uma pandemia que exigia isolamento/distanciamento social, à pere-

\footnotetext{
13“Além da presidência da Caixa, Pedro Guimarães é sócio do banco de investimento Brasil Plural e especialista em processos de privatização. Ele é mais um dos nomes de confiança do ministro da Economia Paulo Guedes". Disponível em: <https://www.sunoresearch.com.br/ tudo-sobre/pedro-guimaraes/>. Acesso em: 24 set. 2020.

${ }^{14}$ Segundo entendimento do STF subsidiárias das empresas públicas sequer precisam da autorização do Congresso para sua privatização. Disponível em: <https://www.gazetadopovo.com.br/republica/subsidiarias-estatais-privatizacao-stf/>. Acesso em: 24 set. 2020.

15 Disponível em: <https://valor.globo.com/financas/noticia/2020/07/23/caixa-faz-planosde-abrir-capital-de-seu-banco-digital.ghtml>. Acesso em: 21 set. 2020.
} 
grinação aos equipamentos da Assistência Social, política totalmente alijada deste processo, com funcionamento reduzido e trabalhadores sem equipamentos de proteção individual (EPI) adequados, em busca de uma inclusão do Cadúnico que passou a ser restrito a agendamento prévio e cuja análise não seria realizada durante a pandemia. Assim também em relação às agências da CAIXA, onde se formaram filas intermináveis para acesso ao benefício e, inclusive, para a solicitação do mesmo, considerando, muitas vezes, a falta de acesso privado a equipamentos, como computador ou celular com internet, e/ou de habilidade para uso desses recursos, cuja "solução", supostamente, foi dada mediante convênio com os Correios. Por fim, aos equipamentos da Justiça, quando esgotadas todas as outras possibilidades e, em muitos casos quando, após o diálogo com assistentes sociais ou com sujeitos integrantes de movimentos sociais e partidos políticos do campo progressista, compreendiam que tal processo significava uma violação dos seus direitos. No governo, assistiu-se ao "jogo de empurra" entre MC, DATAPREV e CAIXA na divisão dos ônus desse processo, especialmente após as inúmeras denúncias de irregularidades, como concessão do AE a usuários fora do perfil, dentre os quais cerca de 73 mil militares das forças armadas.

Tal processo revelou uma lamentável perda de centralidade da política de Assistência Social, processo este que vem ocorrendo progressivamente desde os governos do PT. Cabe lembrar que o MDS era composto por três secretariais nacionais, responsáveis respectivamente pela Assistência Social (SNAS), Segurança Alimentar (SSA) e Transferência de Renda (SNTR). Essa estrutura abriu caminho à autonomização do Cadúnico e do PBF, sob o comando da SNTR.Na transição entre MDS no Governo Dilma/Temer para o MC no Governo Bolsonaro, além da perda de lugar da Assistência Social que, como já citado, se tornou uma subsecretaria da pasta, efetivou também o descolamento do Departamento do Cadastro Único, que passou a integrar a Secretaria Nacional do Cadastro Único, diretamente subordinada à Secretaria Executiva do MC. Contudo, nota-se que tal mudança não resultou em uma maior importância ao Cadúnico para o governo, muito pelo contrário, como foi demonstrado ao longo deste artigo. 
Assim, observa-se um processo de autonomização da transferência de renda em relação à política de Assistência Social e de aprofundamento da sua tendência de financeirização. Esse processo foi iniciado com o Programa Bolsa Família, ainda no ciclo petista, mas ganhou agora a marca deste governo: a total desumanização do processo, com perda de protagonismo da Assistência Social na relação com os usuários, enquanto mediação importante para alguma garantia de direitos para os trabalhadores em uma sociedade capitalista.

\section{Passando a boiada ${ }^{16}:$ o aprofundamento do desmonte da Seguridade Social}

Além de todas as disputas políticas acerca da reabertura das atividades econômicas e do pagamento do $A E$ em um cenário de recessão, o governo, por meio do Ministério da Economia, anunciou a intenção de apresentar ao Congresso, ainda em 2020, duas novas contrarreformas: tributária e administrativa.

Ainda que os projetos de lei, com os textos completos, não tenham chegado às casas legislativas, o debate sobre seu conteúdo e extensão está sendo feito nos bastidores do poder, com parcial revelação dessas negociações pela imprensa.

No caso da contrarreforma tributária, o Brasil está inserido no cenário ultraneoliberal onde, desde a aguda crise de 2008, avançaram a ampliação da desoneração tributária, evasão de lucros para paraísos fiscais e subsídios do fundo público ao capital por meio de empréstimos com juros baixos, privatizações do patrimônio público e contrarreformas nas leis trabalhistas e ambientais para ampliar as possibilidades de exploração e expropriação pelo capital (OXFAM, 2020).

Não é nova a proposta de unificação de tributos sob o discurso de simplificação. São vários os projetos de lei em trâmite, inclusive

\footnotetext{
${ }^{16}$ Expressão utilizada pelo Ministro do Meio Ambiente, Ricardo Salles, em reunião ministerial de 22 abril referindo-se a pandemia como um momento oportuno para a aprovação de leis que flexibilizassem a legislação ambiental no Brasil, favorecendo o neoextrativismo e o agronegócio. Exatos 5 meses depois, um surto de incêndios no Pantanal já havia destruído 141 mil hectares, superando todo o registro histórico do INPE em períodos de seca, sem nenhuma ação efetiva ou investigação de suas causas pelo governo.
} 
elaborados e defendidos pelos governos do $\mathrm{PT}^{17}$. Antes chamado de Imposto sobre o Valor Agregado (IVA) e batizado pelo atual governo de Imposto sobre Bens e Serviços (IBS), sua pretensão é reduzir a cumulatividade dos tributos, cobrando apenas o valor adicionado em cada estágio da produção e da distribuição, e solucionar a chamada "guerra fiscal" entre estados e municípios, atribuindo a cobrança a estados e municípios de destino dos produtos e serviços. Esse discurso, no entanto, esconde a extinção do Orçamento da Seguridade Social. Isto porque, a título de unificação e simplificação, essa lógica tributária acaba com as principais contribuições vinculadas da Seguridade Social: a Contribuição para o Financiamento da Seguridade Social (COFINS) e a Contribuição sobre o Lucro Líquido (CSLL). Na proposta atualmente debatida, o governo pretende acabar com o Imposto sobre Circulação de Mercadorias e Serviços (ICMS) - principal receita dos estados da federação, Imposto sobre Serviços da Qualquer Natureza (ISS) - municipal, Imposto sobre Produtos Industrializados (IPI) cobrado pelo governo federal de produtos nacionais e importados, a já mencionada Cofins e o Programa de Integração Social (PIS) que financia o seguro-desemprego. A unificação desses tributos significa mais centralização tributária na União, que regulará a sua transferência e distribuição entre políticas e entes federativos, além do desmonte da lógica constitucional do orçamento da Seguridade Social.

A normativa constitucional de um orçamento vinculado e exclusivo da Seguridade Social já foi historicamente deteriorado pela Desvinculação das Receitas da União (DRU). Originada como Fundo Social de Emergência (FSE) no governo Cardoso, a desvinculação de receitas foi aprovada e mantida, com maiores e menores percentuais, por todos os governos seguintes (CISLAGHI et al, 2012). A aprovação da contrarreforma tributária, por meio de emenda constitucional, seria o fim definitivo dessa garantia orçamentária da Seguridade Social, que passaria, então, a disputar recursos, de acordo com os ventos conjunturais, com as transferências para estados e municípios, com outras políticas e com o serviço da dívida pública.

17 Disponível em: <https://www.camara.leg.br/noticias/119501-forum-insiste-em-vinculartributos-a-seguridade-e-educacao/>. Acesso em: 23 set. 2020. 
A justificativa do governo é que a desindexação do orçamento permitiria a liberação de recursos para um programa de "distribuição de renda" mais amplo e permanente, nos moldes do auxílio emergencial em substituição ao PBF. Essa argumentação já tinha sido utilizada pelo governo no debate sobre o Fundo de Manutenção e Desenvolvimento da Educação Básica (Fundeb), quando o governo foi contrário à sua renovação ${ }^{18}$, e é só aparentemente contraditória. Como demonstrado na seção anterior a modalidade de política de assistência social proposta por esse governo é clientelista, primeiro damista, focalizada e portanto contrária a todo avanço da estruturação de uma política pública de Assistência Social no país, bem como todas as demais políticas de caráter universal e constitucional compreendidas como direito social e, além disso, favorecedora da financeirização das políticas sociais tornando os mais pauperizados usuários da assistência em "acionistas da miséria”(GRANEMANN, 2007).

A diversidade na base de financiamento da Seguridade Social, sobre a folha de pagamentos, o faturamento e o lucro das empresas, também seria encerrada sob esse imposto único. A regressividade do sistema tributário no Brasil, traço típico do neoliberalismo preconizado desde o Consenso de Washington, se manterá, caso aprovada a contrarreforma, no mesmo patamar, visto que o novo imposto seguiria indireto, ou seja, com incidência no consumo, e portanto, facilmente transferido ao consumidor final dos produtos e serviços. A proposta ainda desonera o capital ao reduzir (ou até mesmo encerrar) a contribuição patronal para a Previdência Social, mais um passo para sua inviabilização como política social e sua entrega para o mercado financeiro.

O país seguirá assim, sob a lógica tributária neoliberal que, cada vez mais, radicalmente abre mão da taxação do patrimônio, das grandes fortunas, e no Brasil até mesmo da totalidade dos dividendos distribuídos a acionistas desde 1995, o que só agudiza as desigualdades sociais no ultraneoliberalismo contemporâneo, que, como apontado, se aprofundaram na pandemia. O que o capital quer no mundo

18 Disponível em: <https://www.terra.com.br/noticias/educacao/com-derrota-para-ogoverno-camara-aprova-novo-

fundeb,03f2a63e2efa8ec0b3a0180e91e51aa9q1d7fhpo.html>. Acesso em: 23 set. 2020. 
inteiro é desoneração tributária associada a draconianas desregulamentações de direitos trabalhistas e legislações ambientais. A crise estrutural não alcança os acionistas do grande capital no ultraneoliberalismo que tiveram um aumento na sua remuneração em $70 \%$ na França, como exemplo, desde a crise de 2008. A crise é transferida para os trabalhadores também por meio da ação dos Estados que isentam e reduzem impostos, fornecem empréstimos a juros baixos, privatizam empresas públicas lucrativas muito abaixo de seu valor. A distribuição da riqueza por meio de dividendos já se ampliou, em 2020, em 3,6\%, num pico sem precedentes, enquanto os Estados garantiram, por meio de fundos públicos, salários e programas sociais para a precária manutenção de alguma renda da maioria dos trabaIhadores em meio a massivas demissões e reduções de jornadas de trabalho (OXFAM, 2020).

A contrarreforma administrativa também em nada é uma proposta inédita, mas, aponta para uma nova rodada da contrarreforma do Estado. É a realização da metáfora utilizada pelo Ministro da Economia na reunião ministerial de 22 de abril, onde disse ser necessário colocar uma granada no bolso dos servidores públicos.

A contrarreforma do Estado, chamada agora administrativa, implementada em várias etapas no período neoliberal, submete o Estado, o fundo público e as políticas sociais ao capital, seja pelo seu sucateamento e redução, abrindo novos espaços para o mercado, seja pela apropriação direta de fundo público, como, por exemplo, por meio dos chamados "novos modelos de gestão" (organizações sociais, fundações públicas de direito privado, empresas públicas), que entregam a gestão do Estado diretamente para organizações privadas ou para estruturas estatais de direito privado que não precisam se submeter aos mesmos mecanismo de controle nem fazer concurso para servidores efetivos regidos pelo Regime Jurídico Único (RJU) .

Os elaboradores da contrarreforma do Estado apresentam a crise do capitalismo como algo não estrutural, mas uma crise dos Estados, considerados hipertrofiados e perdulários, verdadeiros elefantes brancos. Esse discurso é difundido no Brasil desde o fim da ditadura e se capilariza na população atribuindo aos servidores públicos a 
responsabilidade pelo desfinanciamento, corrupção, má gestão e dificuldade de acesso nos serviços públicos.

No Brasil, a contrarreforma do Estado, elaborada e inicialmente implementada no governo Cardoso, acompanha esses pressupostos. Está sistematizada no documento "Plano Diretor da Reforma do Aparelho do Estado", elaborado pelo Ministério da Administração Federal e da Reforma do Estado, capitaneado por Bresser Pereira, e aprovado pela Câmara da Reforma do Estado em 1995 e posteriormente pelo governo da República (BEHRING, 2003).

No momento ultraneoliberal atual, apesar de alegar que as medidas só terão efeitos para futuros servidores, o que o governo propõe é a generalização do fim da estabilidade dos servidores e a implementação da lógica de produtividade e precarização do setor privado. É verdade que os efeitos históricos da contrarreforma do Estado já foram responsáveis pela redução de concursos públicos e pela precarização de contratos por meio de organizações sociais, fundações públicas de direito privado, empresas públicas, terceirizações, principalmente nas políticas de Saúde e Assistência Social. A proposta do governo generaliza essa condição para os novos servidores e altera as formas de avaliação e de progressão de carreira que, se não se aplicarem diretamente aos atuais servidores, generalizarão a situação de múltiplas formas de vínculo, remuneração e direitos dentro da mesma instituição. Em curto prazo, se aprovada a contrarreforma, o país retornará a condições anteriores à Constituição de 1988 quando o trabalho no serviço público dependia de relações políticas clientelistas para uma função desvalorizada e não permanente, piorando ainda mais a continuidade e qualidade dos serviços públicos no país ${ }^{19}$.

\section{Considerações Finais}

Desde a crise de 2008, como momento de agudização da crise estrutural do capital, a combinação de ultraneoliberalismo e ascensão de governos neofascistas vem dando a tônica na conjuntura mun-

\footnotetext{
19 Disponível em: <https://aspuv.org.br/video-andes-sn-debate-impactos-da-reformaadministrativa/>. Acesso em: 23 set. 2020.
} 
dial, inclusive no Brasil, com efeitos cada vez mais perversos para a classe trabalhadora.

A ocorrência da pandemia, oriunda em larga medida dos mecanismos capitalistas de exploração do trabalho e da natureza apresenta-se como o mais recente capítulo dessa crise multifacética que coloca em risco a própria sobrevivência da humanidade.

Ao contrário das perspectivas mais otimistas, o capital tomou a pandemia como momento de oportunidade, ampliando lucros, apropriando-se ainda mais de fundo público e aprofundando o "apocalipse dos trabalhadores".

O parco benefício assistencial que o governo foi obrigado a instituir tornou-se um mecanismo de favorecimento da financeirização com claras expectativas privatizantes posteriores. Para além da tendência antes identificada como "assistencialização das políticas sociais"(MOTA, 2019), o que se coloca em curso hoje é um desmonte definitivo da estrutura pública de toda a Seguridade Social, desde o seu financiamento, para patamares anteriores a Constituição de 1988. Uma caminho de monetarização, financeirização, privatização, focalização, despolitização e ao mesmo tempo, servilidade da força de trabalho, clientelismo, primeiro damismo e refilantropização para o conjunto das políticas sociais, que se acelera e se aprofunda em uma perspectiva cruel e dramática para a classe trabalhadora, sobretudo os seus segmentos mais pauperizados e precarizados.

\section{Referências}

ANTUNES, Ricardo. Podemos viver um ultraneoliberalismo, sob uma ditadura e com respaldo eleitoral. Entrevista. Andes: 2018. Disponível em: <http://portal.andes.org.br/andes/print-ultimas-noticias.andes? id=9729>. Acesso em: 23 set. 2020.

BEHRING, Elaine. Brasil em contrarreforma: desestruturação do Estado e perda de direitos. São Paulo: Cortez, 2003

Ajuste fiscal permanente e contrarreformas no Brasil da redemocratização. In: CISLAGHI, Juliana Fiuza (org). Ajuste fiscal e Seguridade Social: retrocessos e desafios em tempos de ofensiva conser- 
vadora. In IX JORNADA INTERNACIONAL DE POLÍTICAS PÚBLICAS, 2019, (Mesa coordenada). UFMA, Anais..., UFMA, 2019.

CISLAGHI, Juliana Fiuza. O neoliberalismo de cooptação como resposta às resistências. EOL: 2020. Disponível em: <https://esquerdaonline.com.br/2020/06/15/parte-ii-o-neoliberalismo-de-cooptacaocomo-resposta-as-resistencias/>. Acesso em: 23 set. 2020.

, CONCEIÇÃO, Tainá Souza, TEIXEIRA, Sandra Oliveira. O financiamento da saúde no Brasil: principais dilemas. Temporalis, Brasília, ano 12, n.23, jan/jun 2012.

DARDOT, Pierre e LAVAL, Christian. A nova razão do mundo: ensaio sobre a sociedade neoliberal. São Paulo: Boitempo, 2016.

FONTES, Virginia. Crise do coronavírus ou crise do capitalismo? Boitempo: 2020. Disponível em: <https://www.youtube.com/watch? v=YvwS9oAyhUU>. Acesso em: 23 set. 2020.

FRASER, Nancy e JAEGGI, Rahel. Capitalismo em debate: uma conversa na teoria crítica. São Paulo: Boitempo, 2020.

GRANEMANN, Sara. Políticas Sociais e financeirização dos direitos do trabalho. Revista em pauta. n.40. Disponível em: <https://www.epublicacoes.uerj.br/index.php/revistaempauta/article/view/159>. Acesso em: 23 set. 2020.

MÉSZÀROS, Istvan. A crise estrutural do capital. São Paulo: Boitempo, 2011.

MOTA, Ana Elizabete. A cultura da crise e as ideologias do consenso no ultraneoliberalismo brasileiro. In: CISLAGHI, Juliana Fiuza e DEMIER, Felipe (orgs). O neofascismo no poder (ano I): análises críticas sobre o governo Bolsonaro. Rio de Janeiro: Consequência, 2019.

OXFAM. Poder, Lucros e pandemia. Set. 2020. Disponível em:

<https://www.oxfam.org.br/justica-social-e-economica/poder-lucrose-pandemia/>. Acesso em: 19 set. 2020.

SANTOS, Fabio Luis Barbosa dos. Uma história da onda progressista sul-americana (1998-2016). São Paulo: Elefante, 2018. 
SVAMPA, Maristella. As fronteiras do neoextrativimo na América Latina: conflitos socioambientais, giro ecoterritorial e novas dependências. São Paulo: Elefante, 2019.

\section{Sobre as autoras}

Daniele Batista Brandt - Assistente Social pela Universidade do Estado do Rio de Janeiro (2005). Doutora em Serviço Social (2018) e Mestre em Serviço Social (2012) pela Universidade do Estado do Rio de Janeiro. Especialista em Gênero e Sexualidade pelo Instituto de Medicina Social da Universidade do Estado do Rio de Janeiro (2014). Especialista em Política e Planejamento Urbano pelo Instituto de Pesquisa e Planejamento Urbano e Regional da Universidade Federal do Rio de Janeiro (2013). Professora Assistente do Departamento de Fundamentos Teórico-Práticos de Serviço Social da Faculdade de Serviço Social /Universidade do Estado do Rio de Janeiro. E-mail: danielebrandt@yahoo.com.br

Juliana Fiuza Cislaghi - assistente social formada pela Uerj. Mestre e doutora em Serviço Social pelo Programa de Pós-Graduação em Serviço Social da Uerj e especialista em Saúde e Serviço Social. Professora adjunta da Faculdade de Serviço Social da Uerj e pesquisadora do GOPSS - Grupo de Estudos e Pesquisas em Orçamento Público e Seguridade Social, faz pesquisa na área de orçamento público, Seguridade Social, políticas para a educação superior e Serviço Social. E-mail: fiuzajuliana@yahoo.com.br 